\title{
Stillzeit: Zwei Tassen Kaffee sind erlaubt
}

\begin{abstract}
Es war lange umstritten, ob sich Kaffeekonsum während der Schwangerschaft und in der Stillzeit negativ auf das Ungeborene/Neugeborene auswirkt. Jetzt kommt Entwarnung: Moderater Kaffeegenuss scheint sich nicht negativ auszuwirken.
\end{abstract}

— Die Wissenschaftler der Federal University of Pelotas (Brasil) hatten im Jahre 2004885 Mütter zu ihrem Kaffeekonsum während der Schwangerschaft und nach der Geburt sowie den Schlafgewohnheiten ihrer drei Monate alten Säuglinge befragt. Im Durchschnitt nahmen die Frauen 144 mg Koffein täglich $\mathrm{zu}$ sich, das entspricht etwa zwei großen
Tassen Kaffee (ca. 0,5 l). 20\% der Frauen kamen auf über $300 \mathrm{mg}$ Koffein pro Tag während der Schwangerschaft. 14,3\% hatten erst drei Monaten nach der Geburt angefangen, viel Kaffee zu trinken. Ungewöhnlich oft - also mehr als drei-

\section{Kommentar}

Moderater Koffeinkonsum während Schwangerschaft und Stillzeit scheint in den ersten drei Lebensmonaten zumindest den Schlaf der Säuglinge nicht zu beeinflussen. Ein bis zwei Tassen Kaffee pro Tag dürften demnach für stillende Mütter erlaubt sein. Ob größere Mengen Koffein während der Schwangerschaft schädlich sind, bleibt unklar. Und während der Stillzeit sollte man mal pro Nacht - wachten nur 13,8\% (95\%-CI $=11,5-16,0 \%)$ der Babys auf. Bei stillenden Frauen die besonders viel Kaffee tranken, war die Wachfrequenz der Säuglinge leicht - aber nicht signifikant - erhöht.

wohl 300 mg Koffein pro Tag auch nicht überschreiten.

K. MALBERG

\footnotetext{
- I. Santos et al.

(Federal University of Pelotas (Brasil)) Maternal caffeine consumption and infant nighttime waking: prospective cohort study. Published ahead of print, April 02, 2012: doi:10.1542/peds 2011-1773
}

\section{Zungengrundstruma}
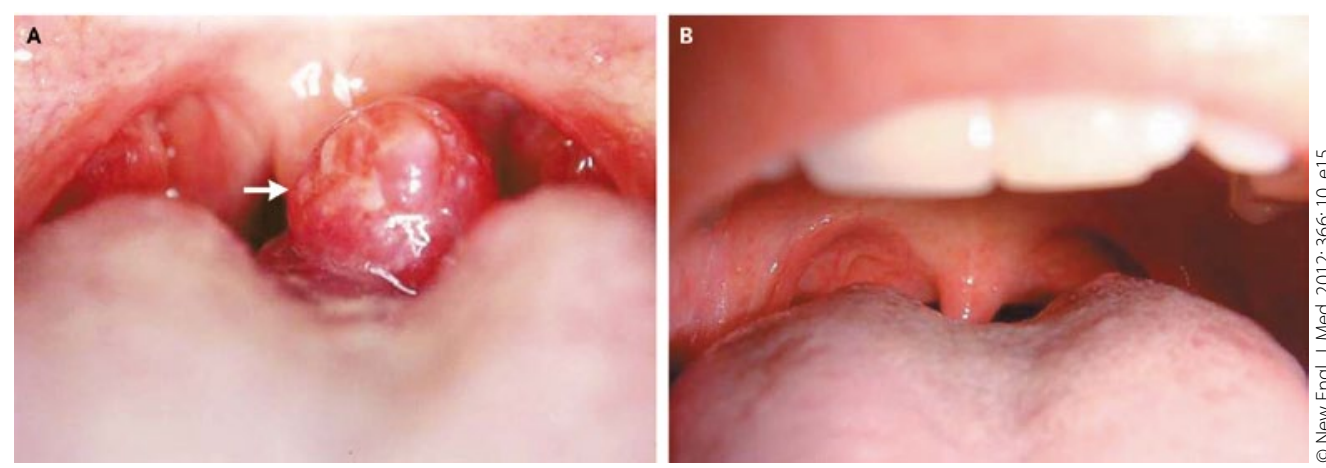

Zungengrundstruma vor (A) und nach Behandlung (B) mit L-Thyroxin.

Eine 45-jährige Frau stellte sich wegen einer lange bestehenden Dyspnoe vor, die insbesondere im Liegen zunahm. Gleichzeitig bestand eine Schluckstörung für feste Speisen.

- Zwei Jahre zuvor war bei der Patientin eine Hypothyreose festgestellt worden. Damals lag die TSH-Konzentration bei $12,8 \mu \mathrm{U} / \mathrm{ml}$ (Normalbereichs 0,25$4,0 \mu \mathrm{U} / \mathrm{ml}$ ). FT4 wurde mit $0,4 \mathrm{ng} / \mathrm{dl}$ gemessen und eine Therapie mit L-Thyroxin begonnen. Beim Blick in den Mund zeigte sich ein derber, hyperämisch wirkender rundlicher Tumor im Bereich des Zungengrundes (Abb. A). Unter einer laufenden Substitution mit $100 \mu \mathrm{g}$ L-Thyroxin pro Tag lag das TSH bei 2,2 $\mu \mathrm{U} / \mathrm{ml}$, das Gesamt-T4 bei $11,9 \mu \mathrm{g} / \mathrm{dl}$ (Normalbereich 6,1-11,8 $\mu \mathrm{g} / \mathrm{dl}$ ) und das Gesamt T3 bei 111 ng/dl (Normalbereich 60-190 ng/dl). Ein Radiojod-Szintigramm mit Jod 131 ergab eine fokale Aufnahme des Tracers an der Zungenbasis, womit die Verdachtsdiagnose einer Zungengrundestruma bewiesen war.
Die Patientin wurde mit $7 \mathrm{mCi}$ Jod 131 behandelt und erhielt zehn Monate danach eine weitere Behandlung mit 10 mCi dieses Radionuklids. Die ektope Struma bildete sich im Lauf von zwei Jahren zurück und damit auch die Schluck- und Atembeschwerden (Abb. B). H. S. FÜESSL =

- Tse-Ya Yu und Tien-Chun Chang (Korresp.: tienchunchang@ntu.edu.tw): Lingual Thyroid. New Engl. J. Med. 2012; 366: $10, \mathrm{e} 15$ 